Original Research Paper

\title{
Influence of Acid Frosting on the Microstructure Characteristics and Mechanical Strength of Eroded Soda- Lime-Silica Glasses by Sandstorm
}

\author{
Akinwumi Gbenga Owoyemi, Grace Olufunke Matthew and Seun Samuel Owoeye \\ Department of Glass and Ceramics, Federal Polytechnic, P.M.B. 5351, Ado-Ekiti, Nigeria
}

\author{
Article history \\ Received: 27-02-2019 \\ Revised: $12-04-2019$ \\ Accepted: 25-04-2019 \\ Corresponding Author: \\ Seun Samuel Owoeye \\ Department of Glass and \\ Ceramics, Federal Polytechnic, \\ P.M.B. 5351, Ado-Ekiti, Nigeria \\ Email: owoeyeseun@gmail.com
}

\begin{abstract}
Most glass products such as cars windshields, solar panels protecting glass and windowpanes are exposed to unavoidable sandblasting effects especially in areas prone to sandstorms. This sand impingement results into micro cracks and surface flaws which altered the structure and strength of the exposed glasses thereby lowering their service life. In this regard, attempt was made in this research to investigate the influence of acid frosting technique as a means of surface modification on the microstructure characteristics and mechanical strength of eroded soda-limesilica glass. Several glass samples measuring 80x60 mm were initially prepared and exposed to sand impingement from a sandblasting machine with an air flow speed of $15 \mathrm{~m} / \mathrm{s}$ and an impact angle of $90^{\circ}$. The sandblasted glass samples $\left(\mathrm{S}_{\text {control }}\right)$ were later immersed in Hydrofluoric Acid (HF) for acid frosting procedure at dipping period of 5, 10, 15 and 20 minutes respectively. Microstructure characteristics were examined using scanning electron microscopy while flexural strength test was conducted to assess the mechanical strength of the sample glasses. The results showed that mechanical strength of the etched-sandblasted samples ( $\mathrm{S}+\mathrm{E}$ series) improve significantly as the dipping period increases compared with sandblasted glasses. In term of microstructure, homogenously distributed micro-cracks and numerous flaws were observed on the eroded glass samples while for the $\mathrm{S}+\mathrm{E}$ series, the stress riser effect of these micro-cracks are well eliminated which accounts for the strength improvement.
\end{abstract}

Keywords: Glass, Sandblasting, HF Etching, Microstructure, Micro-Cracks

\section{Introduction}

Glass is a general term which is commonly given to any solid that exhibits transition temperature near its melting point and that lacks long range structural order (Uhlmann, 1980). Soda-lime-silica glass otherwise known as commercial glass is the most commonly used glasses which constitute over $70 \%$ of world's glass products due to their ease of production, low cost and broad area of applications such as buildings, automobiles, domestic vessels, headlamps, solar panels protective glass, drinks and beverages containers. In theory, glass is a very strong but brittle material with a theoretical strength value of about $7 \mathrm{GPa}$ but in service applications the actual strength value is far lower, failing around $100 \mathrm{MPa}$ (Garza-Mendez et al., 2007). This wide margin observed between the estimated theoretical strength of glass and its actual strength in service has been attributed to various surface flaws, defects and micro-cracks inherent within the glass matrix (Macrell, 2001; Green et al., 2003).

Most commercial glass products such as cars windshields, headlamps, windowpanes, window panels and solar panels protective glass are often exposed to unavoidable sandblasting effects especially in area prone to sandstorms phenomena (desert regions). Continuous exposure to sand impingements induces surface flaws and micro-cracks which causes deterioration of the glass surface. This deterioration of the glass surface thus alters the Microstructural integrity, reduces the overall mechanical strength property and light transmittance of the glass (Bousbaa et al., 2003; Bouaouadja et al., 2000).

Several works have been studied and reported on the erosion of soda-lime glasses by sandblasting effects in order to explain and model sandstorms impingement on 
glass materials (Bouaouadja et al., 2000; Owoeye et al., 2015; Lawn et al., 1997; Wada, 1991) while investigations have been reported on various methods of strengthening soda-lime glasses (Shutov et al., 2002; Master, 1989; Castacon and Gonokhovskii, 2003; Sglavo et al., 1993). However, not many works have been reported on strengthening of sandblasted soda-lime glasses with the aim of eliminating the deteriorating effects resulting from sand impingement (Kolli et al., 2009; Bousbaa et al., 2003). In this regard, this research aims at investigating the influence of acid frosting on the microstructure characteristics and mechanical strength of eroded soda-lime-silica glasses.

\section{Materials and Methods}

\section{Materials}

The starting materials used for this work are flat soda-lime glass with $4 \mathrm{~mm}$ nominal thickness, sand particles and hydrofluoric acid (HF 48\%). The sodalime-silica glass was commercially obtained in its asreceived state while its mean chemical composition, physical and mechanical behavior were based on industrial standard recommended for a typical soda-limesilica glasses. Sands with size range of $0.1-0.3 \mathrm{~mm}$ and particle shapes ranging from spherical to angular peculiar to most eroding sand particles were gotten from beach area typical of sand generated during sandstorms in Nigeria. Hydrofluoric acid solution was obtained in its pure state from Beta Glass Industries in Nigeria.

\section{Sandblasting Process}

Several glass samples measuring $80 \times 60 \mathrm{~mm}$ were initially cut from the as-received flat soda-lime-silica glass and were prepared for sandblasting process. The sandblasting process was carried out using a horizontal sand impingement apparatus in accordance with Yabuki et al. (1999) as shown in Fig. 1. Glass samples were fixed respectively at the sample holder section of the sand blower apparatus and were exposed to sand influx $(20 \mathrm{~g} / \mathrm{min})$ from the machine operated at air flow speed of $15 \mathrm{~m} / \mathrm{s}$ and impact angle of $90^{\circ}$. The glass samples were exposed to the eroding sand particles until the whole surface was covered. A highly blurred appearance was observed due to surface roughness and micro-cracks resulting from sandstorm effects.

\section{Chemical Treatment (Acid Frosting)}

Samples were selected from all the sandblasted glass samples and were immersed in a solution containing 200 $\mathrm{ml}$ of hydrofluoric acid (HF $48 \%$ ) at varying immersion period of 5, 10, 15 and 20 minutes respectively. This acid frosting reaction was carried out in a fume cupboard under room temperature (as shown in Fig. 2). After completion of each immersion period, the glass samples were taken with a pair of laboratory tong and rinsed thoroughly with distilled water. The thoroughly rinsed etched-sandblasted glass samples were later dried at ambient temperature prior to characterization.

\section{Characterization}

Tests such as microstructure examination and flexural strength were carried out in this work to evaluate the microstructure characteristics and mechanical strength of the glass samples respectively. The microstructure examination was investigated using gold coated samples by high performance Phenom Prox Scanning Electron Microscopy (SEM) in order to assess the morphology features. The flexural strength test was carried in relation with ASTM D790 standard at room temperature $\left(25^{\circ} \mathrm{C}\right)$ by a three-point bending strength test using Instron universal testing machine (Instron 3369, 50 $\mathrm{KN}$ load capacity) operated at a strain rate of $5 \mathrm{~mm} / \mathrm{min}$, and a support radius of $2 \mathrm{~mm}$. Load was applied on the sample to obtain a stress rate increase of $0.2 \mathrm{~N} / \mathrm{mm} \mathrm{sec}^{-1}$ until fracture and force obtained at the point of fracture was noted. The tests were conducted in triplicate to establish the reliability of the results.

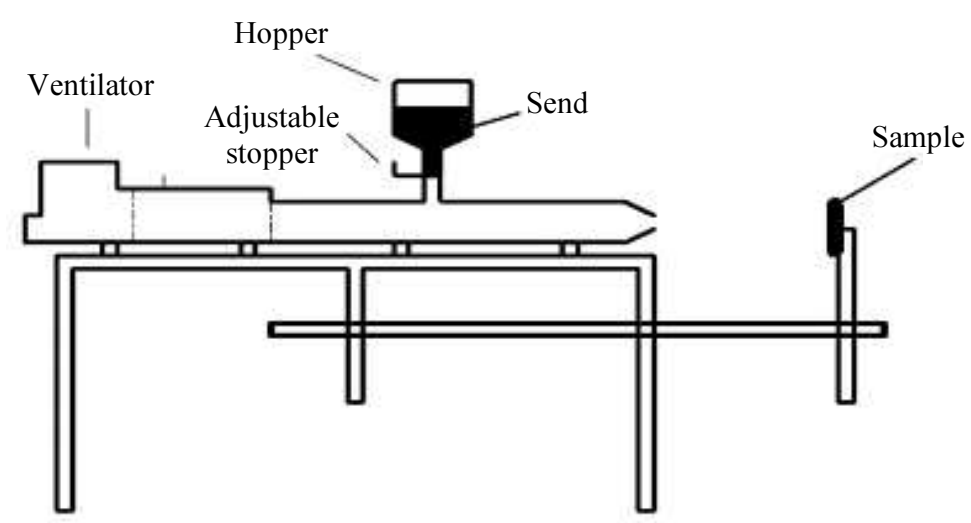

Fig. 1: Sand impingement set up according to Yabuki et al. (1999) 


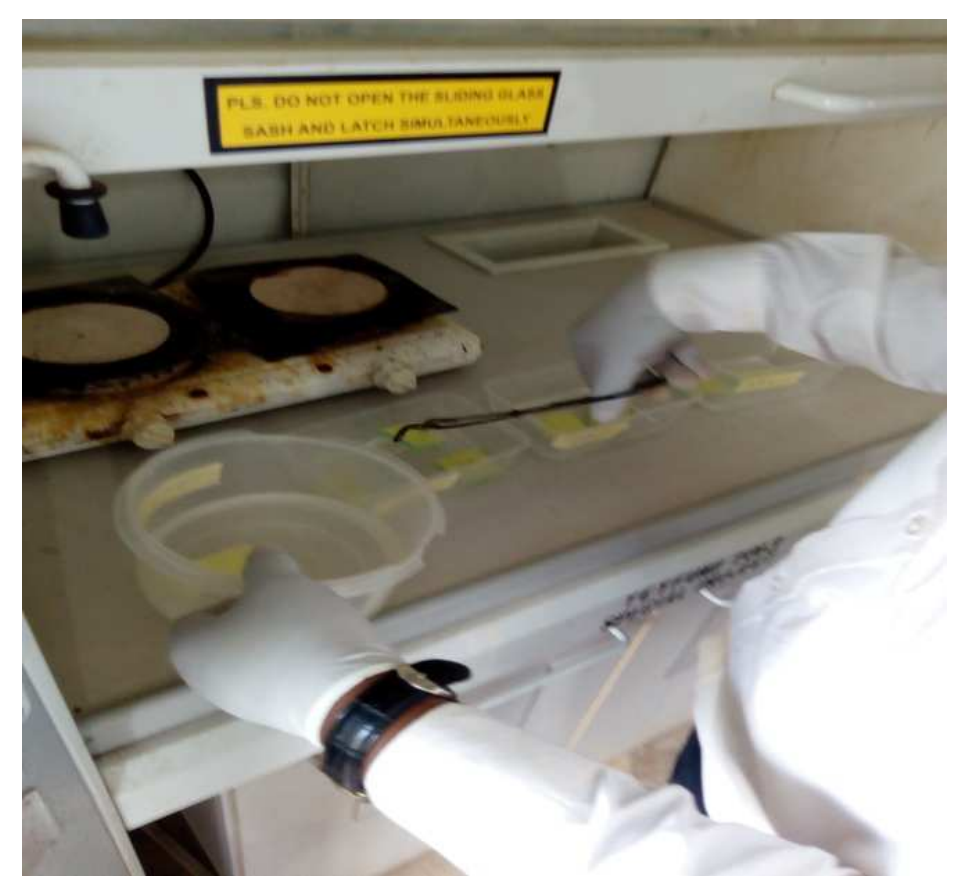

Fig. 2: Acid etching process in fume cupboard

\section{Discussion}

\section{Microstructure Characteristics}

Representative microstructures of the sandblasted glass sample $\left(\mathrm{S}_{\text {control }}\right)$ and etched-sandblasted glass samples ( $\mathrm{S}+\mathrm{E}$ series) are presented in Fig. 3-5 respectively. Representative Secondary Electron (SE) images were used since there is no much difference in the morphology features across the $\mathrm{S}+\mathrm{E}$ series. Figure 3 which represents the morphology of sandblasted glass samples, it was observed that the glass showed a highly damage flawed surface structure which are homogeneously distributed within the glass matrix, micro-cracks and few deteriorated portions were also observed in the glass matrix. These damage flawed and deteriorated portions observed in the glass matrix might be attributed to impact of impingements from eroding sand interacting with the glass surface according to Kolli et al. (2009). Particles were also seen adhering to the glass surface which might be due to sand dusts or glass fragments as stated by Kolli et al. (2009).

Figure 4 presents sandblasted glass samples etched for 10 minutes $\left(\mathrm{S}+\mathrm{E}_{10}\right)$, it can be observed that numerous grain boundaries are seen in the microstructure which can be attributed to the ability of the etchant to encapsulate the surface flaws, blunting and reduction in the length of micro-cracks created by sandblasting. This encapsulation of the surface flaws created numerous surface compressive stresses which are uniformly distributed through the glass matrix. This surface compressive stress has been identified to improve the strength properties of a glass matrix and which has also been reported by Sanya et al. (2018).

Figure 5 which represent the morphology of the glass samples etched for 15 minutes, it can be observed that the microstructure showed similar features as shown in Fig. 4 when the sandblasted samples was etched for 10 minutes. However unlike Fig. 4, the induced surface stresses are more which are homogeneously distributed and the grain boundaries are closer. These features account for the higher strength properties observed at that point than the rest of the samples.

\section{Mechanical Strength}

The results of the flexural strength of the untreated glass and the treated glass samples are shown in Fig. 6. It can be observed that the strength of the normal glass (untreated) sample drastically decreased by $57.5 \%$ from 16.520 MPa to $7.019 \mathrm{MPa}$ (for $\mathrm{S}_{\text {control }}$ ). This drastic reduction in strength can be attributed to presence of damaging flaws, micro-cracks and deteriorated surface observed on the sandblasted glass samples resulting from the eroding impact of sandstorms interacting with the glass surface (Bousbaa et al., 2003; Madjoubi et al., 1999; Bouaouadja et al., 2000; Owoeye et al., 2015). However, it will be observed for S + E series that there is significant increase in the strength of the glass samples when the sandblasted samples were treated in HF acid (acid frosting) for 5, 10, 15 and 20 minutes respectively. 


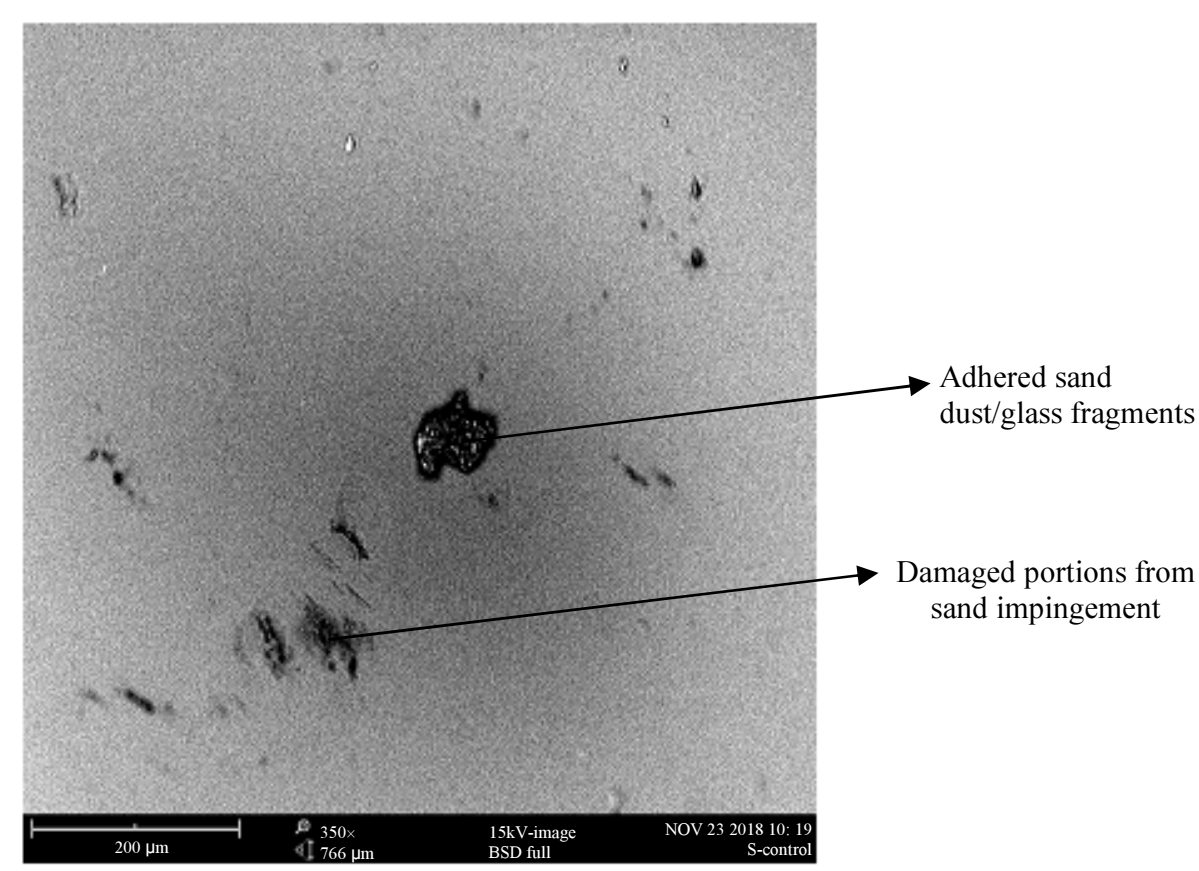

Fig. 3: Representative SE image of the sandblasted glass samples $\left(\mathrm{S}_{\text {control }}\right)$

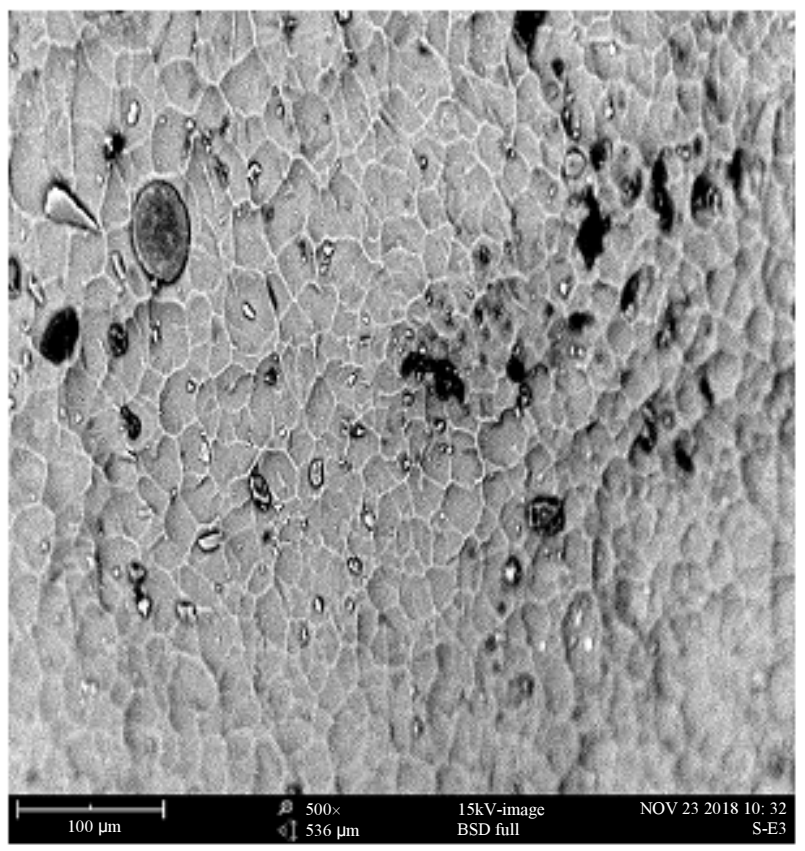

Fig. 4: Representative $S E$ image of sandblasted glass etched for 10 minutes $\left(S+E_{10}\right)$

This significant increase in strength can be attributed to the ability of the etching fluid ( $\mathrm{HF}$ acid) to encapsulate surface flaws, sealing micro-cracks and reducing the length of the micro-cracks initiated by the sand impingements on the glass from sandstorm process. The strength improvement can also be attributed to the surface compressive stresses observed on the glass matrix resulting from acid frosting process (Kolli et al., 2009). These surface compressive stresses create barriers to further propagation of micro-cracks and flaws extension in the glass matrix. However, for sand blasted glass samples etched for 20 minutes (S+E20), a slight drop in strength of about $2.4 \%$ was observed which might indicates that at longer period of acid frosting the acid can in turn be attacking the glass matrix and resulting into re-opening of micro-cracks or the sight decrease could be as a result of measurement errors as reported by Kolli et al. (2009). 


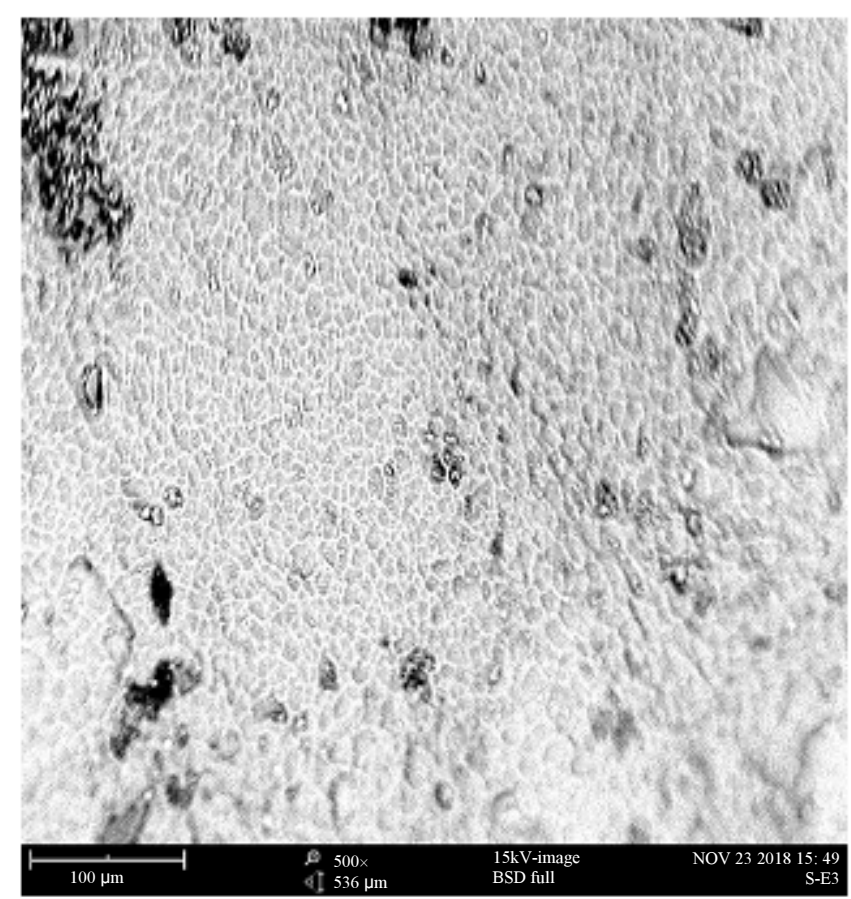

Fig. 5: Representative SE image of sandblasted glass etched for 15 minutes $\left(S+E_{15}\right)$

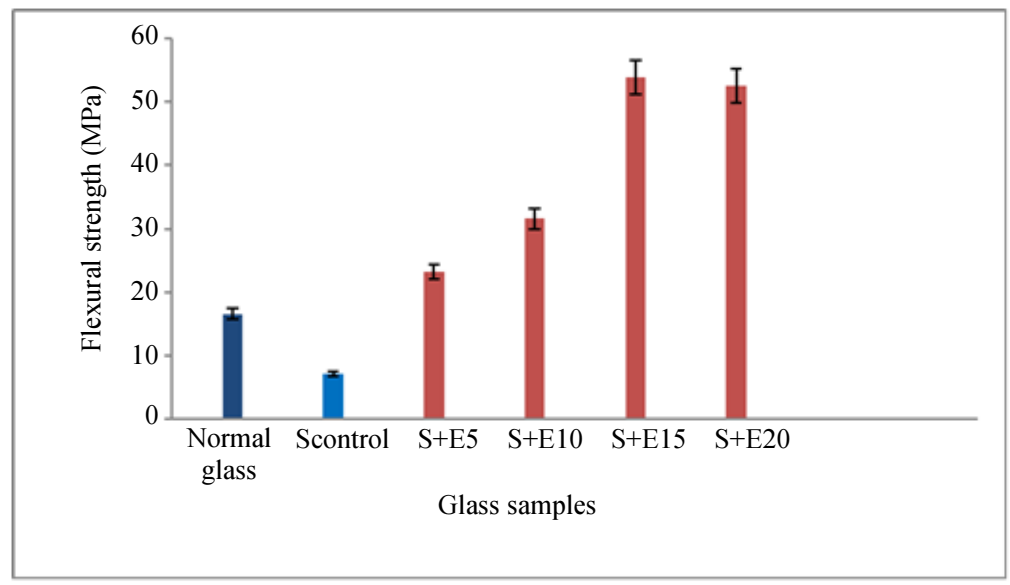

Fig. 6: Flexural strength of the untreated and treated glass samples

\section{Conclusion}

The influence of acid frosting on the microstructure characteristics and mechanical strength of eroded sodalime-silica glasses by sandstorm was investigated. The results show that:

- Sandstorm has a negative effects on the properties of soda-lime glasses especially when used in area prone to such phenomenon

- The strength of the glass samples reduced drastically by $57.5 \%$ when exposed to sandstorms simulated by sandblasting operation
- There is significant improvement in the strength of the $\mathrm{S}+\mathrm{E}$ glass samples and which increased as the immersion period increased

- In terms of morphology, surface flaws, micro-cracks and deteriorated portions characterized the microstructure features of the glass samples exposed to sand impingement from sandblasting while for $\mathrm{S}+\mathrm{E}$ glass samples these surface flaws and microcracks were eliminated to a minimum level due to the surface compressive stresses initiated by the etching fluids creating a barrier to their progression within the glass matrix 


\section{Acknowledgement}

This research did not receive any specific grant from funding agencies in the public, commercial, or not-forprofit sectors.

\section{Author's Contributions}

All the Authors make considerable contributions to conception and design of this work and also give final approval of the version submitted and revised version.

\section{Ethics}

The Authors declare no conflict of interest and that this work has not been published previously anywhere.

\section{References}

Bouaouadja, N., S. Bouzid, M. Hamidouche, C. Bousbaa and M. Madjoubi, 2000. Effect of sandblasting on the efficiencies of solar panels. Applied Energy, 65: 99-105.

Bousbaa, C., A. Madjoubi, M. Hamidouche and N. Bouaouadja, 2003. Effect of annealing and chemical strengthening on soda lime glass erosion wear by sand blasting. J. Eur. Ceram. Soc., 23: 331-343.

Castacon, J.J.T. and A.V. Gonokhovskii, 2003. Properties of coatings obtained in treatment of silicate glasses in potassium and lead nitrate melts. Glass Ceram., 60: 187-189.

Garza-Mendez, F.J., M. HinoJosa-Rivera, I. Gomez and E.M. Sanchez, 2007. Scaling properties of fracture surfaces on glass strengthened by ionic exchange. Applied Surface Sci., 245: 1471-1474.

Green, D.J., V.M. Sglavo and R. Tandon, 2003. US patent 6, 516, 634 B1. Penn State Res. Foundat.

Kolli, M., M. Hamidouche, N. Bouaouadja and G. Fantozzi, 2009. HF etching effect on sandblasted soda-lime glass properties. J. Eur. Ceram. Soc., 29: 2697-2704.
Lawn, B.R., D.B. Marshall and S.M. Wiederhorn, 1997. Strength degradation of glass impacted with sharp particles: II, tempered glass. J. Am. Ceram. Soc. 62: 71-74.

Macrell, G., 2001. Strength issues in chemically strengthened glass. Riv. Stn. Sper. Vetro, 31: 69-76.

Madjoubi, M.A., C. Bousbaa, M. Hamidouche and N. Bouaouadja, 1999. Weibull statistical analysis of the mechanical strength of a glass eroded by sand blasting. J. Eur. Ceram. Soc., 19: 2957-2962.

Master, R.A.,1989. Flat glass tempering-How it works. Glass Industry.

Owoeye, S.S., Y.D. Lamidi and O.J. Ajayi, 2015. Erosive wear assessment of sandstorm on the strength properties of automobile glass. Aca.d Platform J. Eng. Sci., 3: 34-38.

Sanya, O.T., S.S. Owoeye and O.J. Ajayi, 2018. Influence of chemical treatment on microstructure and mechanical properties of chemically-toughened glass by ion exchange process. J. Non-Crystalline Solids, 494: 9-12.

Sglavo, V.M., R. Dal Maschio and G.D. Soraru, 1993. Effect of etch depth on strength of soda-lime glass rods by a statistical approach. J. Eur. Ceram. Soc., 11: 341-346.

Shutov, A.I., I.A. Novikov and S.N. Kramarev, 2002. Glass hardening using the critical air flow, Glass and Ceramics 59: 37-38.

Uhlmann, D.R., 1980. Elasticity and strength in glasses. Gla. Sci. Technol., 5L: 218-251.

Wada, S., 1991. Effect of the fracture toughness of impact particle on the erosive wears of ceramics. J. Jap. Soc. Powder Powder Metall., 38: 893-894.

Yabuki, A. K. Matsuwaki and M. Matsumura, 1999. Critical impact velocity in the solid particles impact erosion of metallic materials. Wear, 233: 468-475. DOI: 10.1016/S0043-1648(99)00170-2 